\title{
A educação superior no contexto da cooperação acadêmica internacional
}

\author{
Higher education in the international academic cooperation context
}

\section{L'enseignement supérieur dans le contexte de la coopération académique international}

\author{
La educación universitaria en el contexto de la cooperación academica \\ internacional
}

\author{
Angela Mara Sugamosto Westphal ${ }^{1}$ \\ Maria Lourdes Gisi ${ }^{1}$
}

Recebido em 23/01/2018; revisado e aprovado em 29/03/2018; aceito em 13/04/2018

DOI: http://dx.doi.org/10.20435/inter.v0i0.1822

\begin{abstract}
Resumo: Este trabalho tem como objetivo analisar a internacionalização da educação superior do Brasil como uma das ferramentas essenciais para o desenvolvimento dos países, ao promover a diminuição das fronteiras culturais, tecnológicas, econômicas e sociais. Trata-se de pesquisa com abordagem qualitativa, realizada mediante análise documental. Discute os resultados obtidos no contexto do processo da Cooperação Acadêmica Internacional em relação à área acadêmica e à pesquisa.
\end{abstract}

Palavras-chave: cooperação acadêmica; internacionalização; educação superior.

Abstract: This work aims to analyze the internationalization of higher education in Brazil as one of the essential tools for countries, development by promoting the reduction of cultural, technological, economic and social boundaries. This is a qualitative approach research, performed through documentary analysis, which discusses the results obtained in the context of the International Academic Cooperation process in relation to the academic area and research.

Keywords: academic cooperation; internationalization; college education.

Résumé: Ce travail vise à analyser l'internationalisation de l'enseignement supérieur au Brésil comme l'un des outils essentiels pour le développement des pays en favorisant la réduction des frontières culturelles, technologiques, économiques et sociales. C'est une recherche avec une approche qualitative, réalisée à travers l'analyse documentaire, qui discute des résultats obtenus dans le cadre du processus de coopération académique internationale en relation avec le domaine académique et la recherche.

Mots-clés: coopération académique; internationalisation; éducation supérieur.

Resumen: Esto trabajo tiene como objetivo analizar la internacionalización de la educación universitária de Brasil como una de las herramientas esenciales para el desarollo de los países al promover la diminuición de las fronteras culturales, tecnológicas, económicas y sociales. Se trata de uma investigación con enfoque cualitativo, realizada mediante el análisis documental, que discute los resultados obtenidos en el contexto del proceso de la Cooperación Académica Internacional en relación al área acadêmica y la investigación.

Palavras clave: cooperación académica; internacionalización; educación universitária.

\section{INTRODUÇÃO}

Este texto tem como objeto de estudo a internacionalização da educação superior com o objetivo de analisar esse processo desde o seu surgimento no país. Para discutir esse processo, é preciso inicialmente fazer uma distinção entre o que se entende por internacionalização e transnacionalização. O pesquisador afirma que "a primeira [...] sendo mais próxima de valores relacionados à solidariedade e à interculturalidade; e a segunda [...] via de regra está associada a processos de mercadorização [...] da educação superior" (AZEVEDO, 2015, p. 56). Mas alerta, com base em Knight (2011), que a internacionalização também carrega seus mitos. Neste estudo, é a

\footnotetext{
${ }^{1}$ Pontifícia Universidade Católica do Paraná (PUC-PR), Curitiba, Paraná, Brasil.
} 
internacionalização da educação superior ${ }^{2}$ que se busca analisar. Argumenta-se que o processo de internacionalização da educação superior tem contribuído com o intercâmbio intercultural, a formação acadêmica e de pesquisadores.

O pesquisador afirma que,

[...] no contexto, dominado pela globalização e pela própria necessidade dos países se globalizarem, surgem iniciativas governamentais para tentar não apenas melhorar o nível educacional de seus respectivos países, mas também igualar ou, pelo menos, reduzir as diferenças que existem entre os sistemas de educação e da pesquisa com outros países. (WESTPHAL, 2014, p. 19).

Como também, se observam influências do mundo globalizado na mercadorização da educação e, nesse contexto, as iniciativas governamentais de cooperação acadêmica internacional correm risco de submeter-se aos ditames do mercado, pois a tendência contemporânea é intensificar o fluxo internacional de bens, serviços, capitais e informações.

As políticas de regulação e atuação da educação superior no Brasil em âmbito internacional têm sido redirecionadas de acordo com os interesses do Norte Global ${ }^{3}$, principalmente pela difusão dos ideais do processo de Bolonha. Um grande exemplo disso, foram os acordos firmados entre o Brasil e diversos países em educação, relativos ao Programa Ciência sem Fronteiras ${ }^{4}$ (CsF).

Como afirmam Knight (2005) e Minogue (1991), a internacionalização da educação é considerada como um processo deliberado de introdução de dimensões internacionais, de caráter intercultural, em todos os aspectos que envolvem as atividades de ensino e pesquisa. A natureza universal do conhecimento, associada à tradição de cooperação acadêmica, no desenvolvimento das atividades de ensino, desde a antiguidade, pode-se considerar como fatores que contribuíram para imprimir caráter internacional à universidade desde a sua origem. Rossato (1998) afirma que, mesmo tendo adotado contornos nacionais, ao ser subordinada aos interesses de cada Estado- Nação (Século XIX), a universidade não anulou sua dimensão universal à medida que os governos nacionais institucionalizaram políticas de cooperação internacional com a implantação de programas de intercâmbio de estudantes, professores e pesquisadores dispostos a fomentar e difundir o conhecimento.

A partir de uma abordagem qualitativa, buscou-se analisar a cooperação acadêmica internacional mediante análise documental que, para Cellard (2010, p. 299-302), pressupõe uma análise crítica do documento considerando cinco dimensões: o contexto no qual foi produzido, os autores e seus interesses, a autenticidade e a confiabilidade do texto, a natureza do texto e por fim os conceitos-chave e a lógica interna do texto. Para tanto partimos d o pressuposto de ser necessário associar e relacionar as fontes selecionadas ao realizar a apreciação das fontes

\footnotetext{
${ }^{2}$ A internacionalização de acordo com a Coordenação de Aperfeiçoamento de Pessoal de Nível Superior (CAPES, 2016) pode ser compreendida como um processo amplo e dinâmico abrangendo o ensino, pesquisa e prestação de serviços para a sociedade.

${ }^{3}$ A maior parte dos países em desenvolvimento se encontram no Sul e os desenvolvidos, no Norte, criou-se a divisão norte-sul. Os países do Norte são caracterizados pelo elevado Produto Interno Bruto (PIB) e pelas condições históricas de poder e acúmulo de riquezas. São representados, em geral, pelos Estados Unidos, União Europeia e Japão.

${ }^{4}$ Ciência sem Fronteiras foi um programa que tinha como objetivo promover a consolidação, expansão e internacionalização da ciência e tecnologia, da inovação e da competitividade brasileira por meio do intercâmbio e da mobilidade internacional. A iniciativa dos Ministérios da Ciência, Tecnologia e Inovação (MCTI) e do Ministério da Educação (MEC). O Programa prévia a concessão de 101 mil bolsas, teve início em 2011 e a última chamada/ edital foi em 2014.
} 
documentais, tais como programas, acordos e relatórios da Coordenação de Aperfeiçoamento de Pessoal de Nível Superior (CAPES). O cruzamento e confronto das fontes foi realizado por meio de uma leitura hermenêutica da documentação e se constitui em operação importante do processo de análise, pois possibilitou uma leitura não apenas literal das informações contidas nos documentos, mas uma compreensão real e contextualizada pelo cruzamento entre fontes que se complementam, em termos explicativos.

A pertinência do estudo se relaciona com o fato de as atividades promovidas no âmbito da educação superior constituírem um fenômeno que tem interessado fortemente ao governo brasileiro e agências de fomento, como a CAPES e Conselho Nacional de Desenvolvimento Tecnológico (CNPq) e as universidades brasileiras, motivo que gerou interesse em analisar esse processo, sem deixar de considerar as influências do mundo globalizado na educação.

\section{MUNDO GLOBALIZADO E SUAS INFLUÊNCIAS NA EDUCAÇÃO}

Para Medeiros (2011), devido à criação de novas tecnologias e redução das barreiras, ocorreu a simplificação da troca de informações, mercadorias e de pessoas. No entanto, apesar dessas prerrogativas, nos defrontamos, no decorrer dos últimos 500 anos, com uma agregação contínua da economia mundial em proveito das classes dominantes, com o contínuo crescimento e da acumulação de capital, por meio das diferenças sociais e regionais de renda e do abuso de diversos países. Modos imperialistas e colonialistas constituíram as principais causas inibidoras do desenvolvimento dos países periféricos e semiperiféricos, provocando dependência política, econômica, financeira e tecnológica, e que impossibilitou o desenvolvimento desses países.

Em Silva, Carneirov e Kosh (2007), aglobalização constitui o estágio máximo da internacionalização e tem como objetivos a uniformização dos centros urbanos, a expansão das corporações além dos seus núcleos geopolíticos, a inovação tecnológica nas comunicações e tecnologia, a reestruturação geopolítica do mundo seja em blocos comerciais, a correlação econômica, política, social e cultural, em nível global.

Em um mundo globalizado, os países se depararam com a necessidade de tomar algumas iniciativas, como firmar mais acordos com instituições internacionais de ensino e de pesquisa, receber professores e pesquisadores visitantes e reformular currículos dos cursos englobando disciplinas ministradas por professores internacionais em inglês, para poder concorrer nesse novo mercado acadêmico e tecnológico.

Esses ajustes e investimento foram necessários para promover a diminuição das barreiras intelectuais, motivar a interação acadêmica e de pesquisa entre os países e consequentemente o aumento da abrangência da cooperação internacional abarcando a educação como um todo, assim como outros ramos, como o econômico e social, com o objetivo de proporcionar desenvolvimento nas nações, afirma Friedman (2009).

Ao analisar o contexto contemporâneo, é fácil perceber que globalização não recai apenas no crescimento da circulação de produtos, capital e serviços entre empresas globais, mas principalmente, na interseção de fronteiras de pessoas. Esse processo diz respeito especificamente à mobilidade humana, e isso se tornou um elemento essencial da economia global devido à procura dos países por empresas e mão obra especializada para melhorar seus serviços e consequentemente sua competitividade. A mobilidade da força de trabalho especializado levou a educação para o campo internacional, ultrapassando as fronteiras e situando o reconhecimento da educação superior no topo da política nacional e internacional. 
Outro ponto importante gira em torno da educação e de como a informação pode contribuir para o desenvolvimento do conhecimento. Segundo Pereira (2001), a educação caminha paralelamente ao desenvolvimento das tecnologias. Na nova economia global, o conhecimento científico está sendo aplicado de forma mais rápida e precisa, e com isso, busca solucionar os problemas de aprendizagem, pois a inteligência, assim como as tecnologias, também não obedece mais a fronteiras ou nacionalidades.

Nesse sentido, Rizvi e Lingard (2010) afirmam que, ao longo das últimas duas décadas, os sistemas educacionais em todo mundo sofreram mudanças significativas, que buscam interpretar e responder ao atual campo de mudanças no contexto econômico, social e político dentro do qual a educação está inserida. As políticas educacionais têm sido profundamente afetadas por estas transformações, processo em que os governos nacionais têm buscado realinhar suas prioridades educacionais ao que eles consideram serem os imperativos da globalização.

A educação superior despertou interesse não só das universidades ou dos governos locais, mas também de novos atores nacionais e internacionais que passaram a ter grande influência no processo de elaboração e implementação de políticas públicas, fazendo com que o papel da educação como responsabilidade do Estado seja cada vez mais questionado como afirmam Leuze, Martens e Rusconi, (2007).

Vale ressaltar que as políticas globais estão sendo transformadas em políticas nacionais, e os interesses dos capitalistas são transformados em políticas públicas, ou melhor, estatais nacionais. Segundo Romão (2008, p. 169), "as políticas do Estado Neoliberal não têm apresentado o caráter público, isto é, voltado para os interesses das maiorias, mas, ao contrário, têm se caracterizado por traços profundamente particulares ou privados, porque se voltam para a satisfação dos interesses da acumulação". O autor destaca que a globalização, ao criar novas conexões internacionais entre as nações e o processo capitalista, gradualmente, internacionalizou os Estados Nacionais ao impor novas obrigações e funções.

Monfredini (2009) afirma que as políticas públicas passaram a atender os interesses globais, ou seja, dos países dominantes. Porém é importante ressaltar que os países não são meros receptores das agendas postas pelas agências multilaterais. Ao contrário, a privatização, o atendimento às regulações do mercado e a diversificação dos sistemas, com todos os efeitos excludentes, inseriram-se na própria constituição do Estado no decorrer do tempo.

A expansão da globalização pode produzir homogeneidade que impeça maior reflexão sobre o que projetamos para o futuro. Por isso, é sempre interessante perguntar o que há por trás das aparências das políticas, dos acordos e tratados, e não se deixar enganar por imagens que fascinam, mas escondem desigualdades e opressões, como ainda a capacidade que tivemos de superar autoritarismos e derrotá-los politicamente. As práticas educacionais também sofrem ameaças dessas práticas fascistas que apagam a implantação de direitos mais amplos e coletivos. (CONSELHOS DE EDUCAÇÃO E DIREITOS HUMANOS [CEDH], 2009, p. 22).

Em entrevista à revista Educação Superior, Boaventura de Sousa Santos ressalta que a economia globalizada alcançou também as universidades e transformou o conhecimento em mais um produto a ser comercializado, afirma Fagundes (2012). Para o sociólogo, a universidade está numa encruzilhada por duas razões: a) ser determinada por uma visão neoliberal, onde os projetos nacionais não são mais o foco e não há uma economia nacional, mas sim uma economia globalizada e; b) aceitar que o conhecimento seja cada vez mais ditado pelas regras do mercado, o que transforma as universidades em empresas. Professores e alunos são tratados como 
operários e clientes, e não como cidadãos da própria universidade. Destarte, as humanidades entram em profunda crise e o conhecimento valorizado é o que interessa ao mercado. Seguindo a mesma discussão, Cowen (2002, p. 40) cita que,

Estas universidades similares a empresas e geridas como negócios competem com outras universidades por prestígio e reputação - mas esse prestígio e reputação estão marcados por instrumentos públicos de mensuração [...]. Do ponto de vista do seu entorno, este tipo novo de universidade se localiza num universo financeiro competitivo, o que significa que deve atrair clientes externos (estudantes, dotações de fundações de pesquisa) para garantir sua continuidade e existência.

Chauí (2001, p. 56) corrobora assinalando que "a universidade está estruturada segundo o modelo organizacional da grande empresa, isto é, tem o rendimento como fim, a burocracia como meio e as leis do mercado como condição". Vale acrescentar que atualmente, não só a universidade brasileira segue esses preceitos, mas também as políticas públicas e a própria organização e gerência do Estado, que promovem a exclusão social intensificada pela globalização neoliberal. Com a mudança do papel do Estado enquanto regulador das políticas educacionais, grupos financeiros e organismos multilaterais passam a controlar ou exercer grande influência nas decisões relacionadas aos rumos da educação superior no Brasil e no mundo.

O espaço social - o enclave da universidade humboldtiana - é invadido e a distância política e econômica entre a universidade e o Estado se dissipa; mais precisamente, é eliminada pelas leis e agências do Estado para criar uma ética de competição e eficiência. Epistemologicamente, este novo tipo de universidade tem que oferecer conhecimentos interessantes para o mercado, vendáveis, ou seja, conhecimentos pragmaticamente úteis. Esta universidade se localiza no âmbito de um mercado do conhecimento e tem de responder às demandas de seus usuários e clientes (por exemplo, os usuários e as agências de financiamento de pesquisa). A produção de conhecimento pela universidade também deve ser mensurável, caso contrário o desempenho não pode ser julgado. Assim, devem ser tomadas decisões gerenciais sobre o valor diferencial de produtos de conhecimento com base em regras e critérios externamente determinados. (COWEN, 2002, p. 40-1).

Segundo Audy (2012), vivemos, provavelmente, o momento da história com mais investimentos destinados à educação e à pesquisa na geração de novos conhecimentos. Por outro lado, os desafios da humanidade são igualmente enormes: os grandes conflitos mundiais, a busca da cura para diversas doenças, as fontes de energias limpas para sustentar o desenvolvimento da sociedade, o alimento sadio e disponível a todos. Se, por um lado, a globalização oferece novas e interessantes oportunidades, por outro ela revela mais claramente as desigualdades e os limites do sistema.

O imaginário da globalização neoliberal levou a uma nova forma de pensar sobre como os sistemas de ensino devem ser governados. Esse ponto de vista da governança ${ }^{5}$ educacional mostra sinais notáveis de convergência em torno de um discurso político de educação local por uma gama de organização internacional, incluindo a Organização para a Cooperação e Desenvolvimento Económico (OCDE), o Banco Mundial (BM) e a Organização das Nações Unidas para a Educação, a Ciência e a Cultura (UNESCO), e abraçou prontamente os sistemas nacionais do hemisfério norte e sul global afirmam Rizvi e Lingard, (2010).

\footnotetext{
${ }^{5}$ Governança é definido como "a maneira pela qual o poder é exercido na administração dos recursos econômicos e sociais do país, com vistas ao desenvolvimento" (WORLD BANK, 1992, p. 1).
} 
No Brasil, o desmonte do Estado-Nação acentua ainda mais a dependência econômica e a desnacionalização das atividades desenvolvidas. Ao se globalizar, a Universidade deixa de ser um "espaço em que as contradições no país poderiam expressar sua identidade e defender os interesses coletivos, expressos numa superação de desigualdade social e na emancipação econômica, política e cultural da maioria de seus habitantes" (ALMEIDA; SOUZA; MANCINI, 2008, p. 195).

É fundamental que a universidade reconstrua o seu ethos público, no sentido de ser uma instituição que perpasse todas as instâncias sociais, convidando os diversos atores sociais para se unirem em torno de um projeto nacional. Portanto é imprescindível "romper com os modelos fechados e quebrar os projetos acabados para colocar a instituição de educação superior num constante processo de aprendizagem, bem como, diluir o paradigma profissionalizante para recuperar a sua dimensão reflexiva" (SÍVERES, 2006, p. 168). Diante da complexidade da expansão da educação superior no Brasil, que ultrapassa as fronteiras nacionais, é necessário que haja estudos e políticas públicas que repensem a perspectiva mercadológica e contribuam para a qualidade acadêmica social.

Impulsionado pelo crescimento econômico na última década, o Brasil alcançou o patamar de 9a economia mundial (WORLD ECONOMIC OUTLOOK DATABASE, 2019), e estimulou a procura do mercado por mão de obra especializada. Assim, a educação superior passou a ocupar grande lugar de destaque nas discussões sobre a necessidade de se formar profissionais qualificados para atender as novas demandas de um país que luta para se firmar entre as grandes potências mundiais. Com a expansão desordenada do número de matrículas nas Instituições de Educação Superior (IES) privadas, o mercado passou a exercer grande influência sobre as políticas educacionais. Esse processo se acelerou após a assinatura do Processo de Bolonha (1999) pela maioria dos países membros da União Europeia (UE), que, sob a égide do Acordo Geral sobre Comércio e Serviços (AGCS), proposto pela Organização Mundial do Comércio (OMC), em 1995, passou a conceber a educação como serviço e não mais como bem comum, afirma Guimarães-Iosif (2009), embora muitos países não tenham assinado o acordo que coloca a educação como um serviço, como foi o caso do Brasil, na prática a educação superior tem tido importante participação de instituições estrangeiras.

Para Rizvi e Lingard (2010), diante da globalização em vigor, há uma notável mudança no modo como a educação é governada. Essa nova dinâmica envolve a passagem de governo para governança. Os governos nacionais não são mais a única fonte de autoridade política e representam os interesses de toda uma gama de atores políticos, tanto nacionais e internacionais, que fazem parte dessa nova concepção de gestão pública e de atuação do Estado.

Essa mudança ocorreu a partir do fim da Guerra Fria e do surgimento da hegemonia do capitalismo neoliberal em escala global e foi encabeçada, na década de 1980, pelos líderes políticos do Reino Unido e dos Estados Unidos (Margareth Thatcher e Ronald Regan) e, mais tarde, apoiada por governos em todo o mundo. Segundo os autores, o governo funciona dentro de um Estado-nação e dentro das estruturas burocráticas do setor público, que controlam as estruturas e as práticas do Estado. Por outro lado, a governança, influenciada pelos princípios da globalização neoliberal, extrapola os limites do Estado-Nação e direciona os governos para uma nova forma de gestão pública, em que novos interesses e atores passam a fazer parte do processo de tomada de decisão.

A nova forma de gestão pública do estado brasileiro foi marcada pelo Consenso de Washington, que recomendou mudanças para que houvesse uma reestruturação econômica 
nos países latino americanos. Segundo Ferreira (2001), em 1989, o Institute for International Economics, entidade privada, convocou representantes do Fundo Monetário Internacional (FMI), Banco Internacional para Reconstrução e Desenvolvimento (BIRD) e do governo dos Estados Unidos da América (EUA) para um encontro em Washington. O objetivo era avaliar as reformas em curso na América Latina. O encontro resultou no Consenso de Washington, e a decisão tomada foi de que os países em questão deveriam promover um conjunto de reformas, tais como: concentração de gastos públicos em atividades voltadas para a educação, saúde e infraestrutura; reforma tributária; liberalização financeira; eliminação das restrições legais à entrada de capitais estrangeiros; privatização das empresas; desregulamentação do trabalho e da legislação. Nesse escopo, a globalização neoliberal, pós Consenso de Washington, fez surgir o atual modelo de gestão pública, que muitos denominam como governança..

\section{COOPERAÇÃO INTERNACIONAL E O DESENVOLVIMENTO}

É de notório saber que, atualmente, o conhecimento é essencial para o desenvolvimento das sociedades capitalistas, e de que, uma forte economia estruturada no conhecimento, não se restringe apenas no acesso à informação, como também no alcance que elas processam a informação, e fazem com que os países reestruturem a organização da educação superior de suas instituições.

O desenvolvimento vai além dos aspectos relacionados ao crescimento dos indicadores econômicos, aumento das receitas, industrialização ou consumo de massa, ele é muito mais abrangente, ou seja, é aquilo que as pessoas podem efetivamente realizar, é influenciado pelos fatores econômicos, pela liberdade política, pelos domínios sociais e pelo acesso à boa saúde, educação de qualidade, e o incentivo e estímulo às suas iniciativas. A efetiva mudança social seria o principal caminho para o desenvolvimento.

N a Resolução n. 41/128 Assembleia Geral da Organização das Nações Unidas, "desenvolvimento" foi conceituado como:

[...] é um amplo processo econômico, social, cultural e político, que objetiva a melhoria constante do bem-estar de toda uma população e de todos os indivíduos na base de sua participação ativa, livre e consciente no desenvolvimento e na justa distribuição dos benefícios dele restante. (DHNET, 1986).

A partir dessa visão global, verifica-se que decisões estratégicas podem interferir no desenvolvimento frente às transformações que ocorreram no mundo nas últimas décadas, como as guerras mundiais, a globalização, a redução das barreiras culturais e econômicas entre os países, o crescimento das tecnologias. Devido à intervenção do Estado, percebe-se que é inconcebível um processo de desenvolvimento em que não esteja prevista a cooperação internacional.

A cooperação internacional é vista como parte integrante da política de um país, principalmente quando se trata de trabalho conjunto entre nações e que tenham como meta o de buscar objetivos que interessam às partes envolvidas. Nas instituições de educação superior, a cooperação acadêmica internacional é a forma pela qual o ensino e a pesquisa crescem e se fortalecem, principalmente por meio de network.

Nesse contexto, a Cooperação Internacional é fator fundamental para o desenvolvimento da ciência brasileira e mundial; no Brasil, um exemplo disso, foi o crescimento de acordos bila- 
terais internacionais firmados pelas agências fomentadoras brasileiras em 2011, por meio do Programa Ciência sem Fronteiras.

Esse crescimento foi impulsionado, não só pelas consequências da globalização, mas sim, pela necessidade de conquistarmos alguns avanços tecnológicos e científicos, de potencializarmos nossas riquezas naturais estratégicas, e claro, o próprio desenvolvimento nacional com projeção no cenário internacional.

É importante salientar que a produção conjunta de conhecimento é a forma mais elaborada de cooperação acadêmica. Normalmente, antes da realização dessa produção, é necessário que outras redes tenham sido efetivadas para que se constituam grupos de ambos os lados a fim de realizar o projeto de pesquisa. Os acordos bilaterais são programas que fomentam projetos conjuntos de pesquisa entre grupos brasileiros e estrangeiros. São financiadas missões de trabalho (intercâmbio de professores), bolsas de estudo (intercâmbio de alunos), além de uma quantia para o custeio das atividades do projeto, afirma Morosini (2011).

Em relação ao desenvolvimento e respeito a sua expansão de atividades internacionais, a colaboração com parceiros no exterior está sendo ainda mais fortalecida e a sustentabilidade da internacionalização da pesquisa e da pós-graduação brasileiras mais valorizada. Foram realizadas ampliações com algumas agências congêneres por meio de associações com outros países como forma de visar à concessão de bolsas, não apenas como solicitações individuais, como também a partir das demandas de grupos de pesquisas e instituições de educação superior, de demandas governamentais, estas em especial por meio da interação com o Ministério das Relações Exteriores conforme cita CAPES (2017a).

\section{COOPERAÇÃO INTERNACIONAL NO BRASIL}

Na pós-graduação a Cooperação Internacional é regulada basicamente pela CAPES e pelo CNPq. Ambas as agências vêm atuando em áreas parecidas. A CAPES, fundação do Ministério da Educação (MEC), é voltada para a formação de recursos humanos de alto nível em todas as áreas do conhecimento. O CNPq, agência do Ministério da Ciência, Tecnologia e Inovação (MCTI), é destinada ao fomento da pesquisa científica e tecnológica e à formação de recursos humanos para pesquisa no país.

O pesquisador afirma que "a Cooperação Internacional tornou-se um fator fundamental para o incremento da ciência brasileira e mundial, justamente nesse período em que a educação está sendo considerada prioritária nas sociedades que se internacionalizam e são impulsionadas rapidamente devido à era da globalização, que por si só, diminui fronteira, tornando qualquer tipo de contato mais rápido, fácil e eficaz" (WESTPHAL, 2014, p. 55).

Durante todo o desenvolvimento da CAPES, a Cooperação Internacional sofreu e ainda sofre modificações e adequações ao mercado e necessidades internas e mundiais. Nesse sentido, a comunidade acadêmica que pleiteia essa cooperação tornou-se mais exigente no que diz respeito às suas expectativas e mudou seus objetivos com relação a esse tipo de intercâmbio. Schmidt (2005) relata que a Cooperação Internacional da CAPES ocorreu em três etapas. A primeira fase foi do Programa Universitário, nesse período a cooperação era individualizada, visivelmente assimétrica e era marcada pelo apoio estrangeiro para o desenvolvimento do sistema de educação superior e para a capacitação de estudantes no exterior, como cita Canto (2005). Para Schmidt (2005), essa primeira fase iniciava-se com a criação das universidades brasileiras, 
em especial com a influência da cooperação francesa, que atuou na criação da USP nos anos 1930, indo até década de 1970.

Na segunda fase, segundo Rosa (2008), a CAPES possuía alguns poucos acordos de Cooperação Internacional, no entanto, com intensa atividade em grupos investigadores, como o CAPES/Comitê Francês de Avaliação da Cooperação Universitária com o Brasil (COFECUB) com a França, que financiava 79 projetos conjuntos de pesquisa entre dois países, CAPES/Serviço Alemão de Intercâmbio Acadêmico/Deutscher Akademischer Austauschdienst (DAAD) com a Alemanha

Essa segunda fase durou quase 20 anos e caracterizou-se por um regime de colaboração internacional parcial, corrobora Schmidt (2005), uma vez que o fluxo de estudantes, com raras exceções, ainda não exercia grande interesse nos países de ponta, sendo o interesse, àquela época, muito maior pelas nossas riquezas naturais estratégicas do que pela nossa produção científica propriamente dita. Na virada do século XX, entra-se na terceira fase, quando a situação anterior se altera substancialmente.

A partir dessa terceira fase, foram iniciados os programas de parcerias universitárias ${ }^{6}$ binacionais, mais especificamente iniciados em 2001 com o objetivo de aumentar o intercâmbio de estudantes de graduação e como forma de fomentar o intercâmbio de alunos de pós-graduação e professores entre as universidades brasileiras e estrangeiras como fundamental garantia para o reconhecimento mútuo de crédito aos alunos perante a área escolhida pelo projeto.

No final de 2007, foi instituída na CAPES a Diretoria de Relações Internacionais (DRI) tendo como funções a coordenação dos programas de bolsa no exterior e a coordenação de Cooperação Internacional.

A antiga Coordenação de Relações Internacionais tornou-se Diretoria de Relações Internacionais (DRI), diversificando acordos, programas e projetos relacionados à Cooperação Internacional e negociação de atos internacionais com organismos, entidades e governos estrangeiros, para promover ações bilaterais e multilaterais para a qualificação de Recursos Humanos, promover a modernização de currículos e disciplinas de graduação por meio do intercâmbio de estudantes e professores entre as instituições participantes nos programas de cooperação, internacionalizar a pós-graduação e construir redes de cooperação, com também, contribuir para o desenvolvimento de áreas de conhecimento ainda não consolidadas na graduação e pós-graduação no País.

Segundo Velloso (1991), um regime de colaboração assimétrica ocorre a partir da terceira fase com cooperação calcada em uma simetria de ações e de financiamento. Essa fase é tipificada por mecanismos mais complexos de cooperação, não denotando assistência, mas um trabalho conjunto em programas de pesquisa (laboratoriais compartilhados) e intercâmbio de docentes e estudantes conectados a tais projetos.

Essa colaboração assimétrica ocorre também por meio de projetos conjuntos de pesquisa, que têm como objetivo o desenvolvimento de núcleos de pesquisa em cooperação internacional entre instituições de educação superior do Brasil e do exterior.

Esses programas buscam ainda a aproximação das estruturas curriculares entre as instituições e os cursos participantes. Os acordos internacionais com programas ativos em 2016 são

\footnotetext{
${ }^{6}$ As parcerias são implementadas entre universidades brasileiras e estrangeiras, tendo como princípio base o reconhecimento mútuo de créditos cursados pelos alunos participantes, na área escolhida pelo projeto. Busca-se a aproximação das estruturas curriculares entre as instituições e cursos participantes, bem como o estímulo à mobilidade acadêmica internacional.
} 
com os seguintes países: África, Alemanha, Áustria, Argentina, Bélgica, Canadá, Cuba, Espanha, Estados Unidos, França, Países Baixos, Israel, Itália, Japão, Noruega, Portugal, Reino Unido, Suécia, Timor leste, Uruguai e Multinacional como afirmam Rosa (2008) e CAPES (2008).

A execução de projetos conjuntos de pesquisa da Cooperação Acadêmica Internacional se dá por intermédio do financiamento missão de trabalho, realizada pelos coordenadores de projetos, seus parceiros em rede e demais pesquisadores vinculados. Isso consiste em visitas de curta duração à sede do parceiro para o desenvolvimento de atividades relacionadas ao objetivo da parceria, e por missão de estudos que trata da seleção e alocação de estudantes no exterior, concedendo bolsas de estudos individuais para alunos vinculados ao projeto.

A CAPES financia missões de trabalho (intercâmbio de professores), bolsas de estudo (intercâmbio de alunos), além de uma quantia para o custeio das atividades do projeto. Para tal, é imprescindível que os grupos de pesquisa brasileiros estejam ligados a programas de pós-graduação reconhecidos pelo MEC, preferencialmente com conceitos 5, 6 ou 7 na última avaliação da CAPES (2008).

Além disso, a Cooperação Acadêmica Internacional possibilita o intercâmbio de pesquisadores, docentes e discentes e a constituição de redes de pesquisa internacionais, como parte da missão da CAPES, o que constitui um importante instrumento à ampliação da competência científico-tecnológica do País. A intensificação das atividades da Cooperação Internacional da CAPES pode ser demonstrada pela diversidade de modalidades de fomento que coexistem na agência, variando desde ações de caráter assistencial até atividades de cooperação em parcerias cada vez mais simétricas.

A Cooperação Internacional na CAPES é feita por meio de tratados e acordos culturais, educacionais e científicos que determinam o surgimento de programas de intercâmbio internacional.

Outros acordos de Cooperação Internacional firmados entre a CAPES e agências congêneres no exterior são os Projetos Conjuntos de Pesquisa (PP). Tais acordos são formulados com a identificação de áreas de interesse comum, tendo como princípios básicos simetrias nos orçamentos e nas mobilidades de pesquisadores, docentes, pós-doutorados e estudantes de pós-graduação.

Essa linha de ação deve, sem exceção, contemplar a participação e mobilidade de alunos, condição essa considerada requisito mínimo para aprovação de projeto submetido. O apoio a essa modalidade visa promover o desenvolvimento científico e a formação de recursos humanos altamente qualificados. Exemplos clássicos dessa modalidade são os programas CAPES/Ministério de Ciência, Tecnologia e Inovação Produtiva da República Argentina (MINCYT) e CAPES/COFECUB, que há anos promovem a parceria entre pesquisadores brasileiros e pesquisadores argentinos e franceses, respectivamente como afirma Westphal (2014).

Nesse contexto, seguem as Parcerias Universitárias (PU) com os mesmos princípios básicos dos projetos conjuntos de pesquisa, tanto no que diz respeito ao financiamento recíproco e simetrias nas mobilidades, como na definição dos temas de interesse comum entre os parceiros. Entretanto diferenciam-se por seu caráter acadêmico, voltado para a mobilidade de estudantes, principalmente em nível de graduação, e para a modernização e adaptação recíproca de grades curriculares, além de estimular, enfaticamente, a dupla diplomação dos alunos.

O Programa de Bolsas e Auxílio no Exterior da CAPES admite a inserção de brasileiros em centros de desenvolvimento científico e tecnológico no exterior, para a realização de estudos e pesquisas, bem como estimula a participação em eventos científicos no exterior, visando contribuir principalmente com a internacionalização da educação superior brasileira. Por ser uma 
das agências que mais fomenta bolsas no exterior, a CAPES vem buscando melhores condições aos estudantes e às suas pesquisas nas universidades do mundo, contribuindo assim, de forma ativa, o crescimento do País em ter, cada vez mais, excelência nas suas universidades, afirma Fernandez (2012).

Na maior parte dos casos, os programas de cooperação internacionais são financiados pela CAPES ou outras agências de fomento brasileiras. Esses programas suportam projetos direcionados à cooperação internacional com os país com que a instituição tem acordo, principalmente no que diz respeito ao custeio da mobilidade acadêmica.

Em 2016, a CAPES apoiou aproximadamente 19.380 alunos por meio da concessão e da manutenção de bolsas de estudos para brasileiros no exterior e para estrangeiros no Brasil, nas diversas modalidades fomentadas pela agência, além do apoio a 958 projetos de pesquisa e missões de trabalho. Essas ações se deram no âmbito dos cerca de 100 programas geridos pela Diretoria de Relações Internacionais. Para 2017, está previsto o apoio a aproximadamente 13.200 bolsistas e mais de 1.500 projetos citado em CAPES (2016).

Esse apoio diz respeito a várias modalidades de bolsa no exterior podendo ser bolsas individuais, institucionais, vinculadas a projetos ou parcerias universitárias. As bolsas são provenientes de programas específicos, definidas por meio de acordos de cooperação específicos ou de apoio à proatividade individual do pesquisador ou discente. Como reciprocidade nos projetos binacionais, é prevista a concessão de bolsa no País para estudantes de estrangeiros de graduação sanduíche em programas específicos, bem como objetiva atrair pesquisadores e docentes do exterior.

O pesquisador afirma que "a CAPES também apoia, por meio de programas no âmbito da cooperação para o desenvolvimento, o incremento estrutural da educação em países em situações de severas dificuldades econômicas e sociais. Essas ações decorreram principalmente por meio dos programas de cooperação Sul-Sul, destacando-se os programas Programa de Estudante Convênio de Pós-Graduação- multilateral (PEC-PG), Programa de Formação Científica- Angola, Cabo Verde, Moçambique (PROFOR), Programa de Qualificação de Língua Portuguesa no Timor Leste Pró-Haiti, (PQLP) e Universidade Aberta do Brasil (UAB)-Moçambique" (WESTPHAL, 2014, p.59).

A cooperação internacional é um componente estratégico da missão da CAPES. Desse modo, a CAPES, especificamente a Diretoria de Relações Internacionais (DRI), foca na formação de recursos humanos de alto nível visando à inclusão de brasileiros no meio acadêmico, científico e tecnológico internacional citado em CAPES (2017b).

O processo de internacionalização das instituições de educação superior (IES) brasileiras avançou nos últimos anos, mas são necessários ajustes para torná-lo mais eficiente. Esse é o resultado do Questionário Aplicado pela CAPES sobre a Internacionalização na Universidade Brasileira. De acordo com o estudo, existe no Brasil uma tendência à internacionalização passiva (mobilidade de docentes e discentes para o exterior), com baixas taxas de atração de profissionais internacionais. Isso ocorre apesar de as IES já apresentarem a atração de professores estrangeiros entre as prioridades do processo de internacionalização. A forma como o conhecimento adquirido no exterior vem sendo difundido e aproveitado nas instituições brasileiras também pode se desenvolver, pois apenas parte das instituições afirmou incluir os profissionais qualificados no exterior em seus Programas de Pós-Graduação (PPG) como é afirmado em CAPES (2017a). 


\section{CONSIDERAÇÕES FINAIS}

A cooperação internacional é vista como elemento necessário da política pública para a educação de um país, um trabalho conjunto entre nações que tem como intuito colaborar na execução de objetivos de interesses comuns entre os envolvidos.

O estudo deixa evidente essa importância ao considerar que a internacionalização tem contribuído com a formação de pesquisadores e a de construir redes de cooperação, como também contribuir para o desenvolvimento de áreas de conhecimento, ainda não consolidadas na graduação e pós-graduação no País. A intensificação da internacionalização é recente, uma vez que somente em 2001 teve efetivamente início, mas sua evolução é evidente, embora se façam necessários ajustes, mas não se podem perder os avanços já obtidos.

A política recente de corte de gastos certamente poderá comprometer os esforços realizados com a internacionalização da educação superior, assim como também os relacionados à pós-graduação stricto sensu. O intercâmbio intercultural, a formação de pesquisadores e o aprimoramento na formação de estudantes de graduação é fundamental para o avanço da ciência e, portanto, para o desenvolvimento da sociedade, a ssim como o intercâmbio com países com dificuldades econômicas e sociais tem sido uma iniciativa que evidencia o esforço do Brasil em contribuir com a superação de desigualdades sociais entre países.

\section{REFERÊNCIAS}

ALMEIDA, Maria de Lourdes de; SOUZA, André Peixoto de; MANCINI, Fabrízio Nicolai. Estado, política e educação: a exclusão sob o impacto da demanda do mercado na universidade brasileira. In: ALMEIDA, Maria de Lourdes de; BONETI, Lindomar Wessler (Org.). Educação e cidadania no neoliberalismo: da experiência à análise crítica. Campinas, SP: Mercado das Letras, 2008. p. 189-200.

AUDY, Jorge Luís Nicolas. A internacionalização na educação. Revista Digital.com.br, Brasil, 2012. Disponível em: https://www.revistadigital.com.br/2012/04/a-internacionalizacao-na-educacao/. Acesso em: dez. 2017.

AZEVEDO, Mário Luiz Neves. Transnacionalização e mercadorização da educação superior: examinando alguns efeitos colaterais do capitalismo acadêmico (sem riscos) no Brasil-A expansão privado- mercantil. Revista Internacional de Educação Superior, Campinas, SP, v. 1, n. 1, p. 86-102, jul./set. 2015. https://doi. org/10.22348/riesup.v1i1.7371

CANTO, Isabel. O Brasil e a evolução da colaboração científica internacional. In: SARAVAIA, José Flávio Sombra; CERVO, Amado Luís (Org.). O crescimento das relações internacionais no Brasil. Brasília: Teixeira Gráfica e Editora, 2005.

CAPES. Retrospectiva: Capes divulga números de 2016. 2017a. Disponível em: http://www.capes.gov.br/ sala-de-imprensa/noticias/8254-capes-divulga-numeros-de-2016. Acesso em: 30 out. 2017.

CAPES. A internacionalização na Universidade Brasileira: resultados do questionário aplicado pela Capes. Edição e composição: Diretoria de Relações Internacionais. Brasília, 31 de outubro 2017b. Disponível em: http://capes.gov.br/images/stories/download/diversos/A-internacionalizacao-nas-IES-brasileiras.pdf . Acesso em: 1으ov. 2017.

CAPES. Modalidade de bolsas. 2016. Disponível em: http://www.capes.gov.br/bolsas-e-auxiliosinternacionais/modalidades-de-bolsas. Acesso em: 15 set. 2017.

CAPES. Cooperação internacional. 2008. Disponível em: https://www.capes.gov.br/cooperacaointernacional. Acesso em: 15 set. 2017. 
CELLARD, André. A análise documental. In: POUPART, J. et al. A pesquisa qualitativa: enfoques epistemológicos e metodológicos. 2. ed. Petrópolis, RJ: Vozes, 2010.

CHAUÍ, Marilena de Souza. Escritos sobre a universidade. 1. ed. São Paulo: Fundação Editora da UNESP, 2001.

CONSELHOS DE EDUCAÇÃO E DIREITOS HUMANOS (CEDH): diálogos da contemporaneidade. Brasília: Ministério da Educação, Secretaria de Educação Básica, Secretaria Especial dos Direitos Humanos, 2009. Disponível em: http://portal.mec.gov.br/dmdocuments/projetoseducacionais.pdf. Acesso em: nov. 2017.

COWEN, Robert. A crise da universidade: uma nota comparativa sobre gestão e uma observação para o Brasil. Editora Em Aberto, Brasília, v. 19, n. 75, p. 35-48, jul. 2002. Disponível em: http://emaberto.inep. gov.br/index.php/emaberto/article/view/2166.

DHNET. Declaração sobre o direito ao desenvolvimento. Resolução n. 41/128. Assembleia Geral da Organização das Nações Unidas, 1986. Disponível em: http://www.dhnet.org.br/direitos/sip/onu/bmestar/ dec86.htm. Acesso em: 10 dez. 2017.

FAGUNDES, Lygia. O caminho do meio. Revista Ensino Superior, São Paulo, v. 14, n. 161, p. 14-7, fev. 2012.

FERNANDEZ, Eloisa. Estudo dos ex-bolsistas inadimplentes de doutorado pleno no exterior: motivos e causas do insucesso caso CAPES. 2012. 81p. Dissertação (Mestrado em Educação em Ciências) - Universidade Federal de Santas Maria (UFSM), Santa Maria, RS, 2012.

FERREIRA, Alceu Conceição. As Agências Multilaterais e a política econômica do governo FHC. In: FERREIRA, Alceu Conceição; ALVIM, Valdir (Org.). A trama da privatização: a reestruturação neoliberal do Estado. Florianópolis, SC: Insular, 2001. p. 29-48.

FRIEDMAN, Thomas Loren. O mundo é plano - uma breve história do século XXI. 3. ed. São Paulo: Objetiva, 2009.

GUIMARAES-IOSIF, Ranilce Mascarenhas. Educação, pobreza e desigualdade no Brasil: impedimentos para a cidadania global emancipada. 1. ed. Brasília: Líber Livro, 2009.

KNIGHT, Jane. Five myths about internationalization. International Higher Education, n. 62, Winter 2011.

KNIGHT, Jane. Higher education: handbook of theory and research. 1. ed. Nethrelands: Springer, 2006.

KNIGHT, Jane. Model of internationalization and how to deal with new realities and challenges. In: OCDE. L'enseignement supérieur en Amérique Latine - la dimension internationale. 1. ed. Paris: Organization de Coopération et de Développement Économique, 2005.

LEUZE, Kathrin; MARTENS, Kerstin; RUSCONI, Alessandra. New arenas of education governance - the impact of international organizations and markets on education policy making. In: MARTENS, Kerstin; RUSCONI, Alessandra; LEUZE, Kathrin (Ed.). New arenas of education governance: the impact of international organizations and markets. 1. ed. New York: Palgrave Macmillan, 2007.

MEDEIROS, Ana Rosa de Brito. A cooperação internacional como fomentadora do desenvolvimento. Âmbito Jurídico, Rio Grande, RS, XIV, n. 89, jun. 2011. Disponível em: http://www.ambito-juridico.com. $\mathrm{br} / \mathrm{site} /$ ?n_link=revista_artigos_leitura\&artigo_id=9635\&revista_caderno=16. Acesso em: jan. 2018.

MINOGUE, Kenneth. O conceito de universidade. 1. ed. Brasília: Editora EdUNB, 1991.

MONFREDINI, Ivanise. Políticas de Ensino Superior no Brasil: aspectos históricos e teóricos-metodológicos para o estudo das alternativas. In: ROMAO, José Eustáquio; MONFREDINI, Ivanise (Org.). Prometeu desencantado. A Educação Superior na IberoAmérica. 1. ed. Brasília: Líber Livros, 2009. 
MOROSINI, Maria Cristina. Internacionalização na produção de conhecimento em IES brasileiras: cooperação internacional tradicional e cooperação internacional horizontal. Educação em Revista, Belo Horizonte, v. 27, n. 1, p. 93-112, 2011.

PEREIRA, Ana Maria. Informação, globalização e educação: desafios de uma nova era. Informação \& Informação, Londrina, PR, v. 6, n. 2, p. 91-8, jul./dez. 2001.

RIZVI, Fazal; LINGARD, Bob. Globalizing education policy. 1. ed. New York: Routledge, 2010.

ROMÃO, José Eustáquio. Globalização e reforma educacional no Brasil (1985 - 2005). Revista Iberoamericana de Educación, n. 48, p. 111-127, 2008.

ROSA, Leonardo Osvaldo Barchini. Cooperação acadêmica internacional: um estudo da atuação da CAPES. 2008. 140p. Dissertação (Mestrado em Ciências Sociais)- Universidade de Brasília (UnB), Brasília, DF, 2008.

ROSSATO, Ricardo. Universidade: nove séculos de história. Passo Fundo, RS: Ediupf, 1998.

SCHMIDT, Benício Vierio. Cooperação internacional e reforma universitária no Brasil. Agosto de 2005. Não publicado.

SILVA, Adriano Lazzari; CARNEIROV, Diego Baumgarten; KOCH, Carlos Francisco Coelho. Globalização. Comunidade ADM. Porto Alegre, RS, 24 de novembro de 2007. Disponível em: http://old.administradores. com.br/artigos/economia-e-financas/globalizacao/20501/. Acesso em: 20 out. 2017.

SILVA, Stella Maris Wolff da. Cooperação Acadêmica Internacional da Capes: perspectivas do Programa Ciência sem Fronteiras. 2012. 113p. Dissertação (Mestrado em Ensino) - Universidade Federal do Rio Grande do Sul (UFRGS), Porto Alegre, 2012.

SÍVERES, Luís. Universidade: torre ou sino? 1. ed. Brasília: Universa, 2006.

VELLOSO, Jacques. Custos reais e custos contábeis da universidade pública. In: VELLOSO, Jacques. Universidade pública: política, desempenho, perspectiva. São Paulo: Papirus, 1991. p. 177-222.

WESTPHAL, Angela Mara Sugamosto. Egresso da primeira Chamada do Programa "Ciência sem Fronteiras": reflexos no sistema educacional brasileiro (Learning with outcomes). 2014. 120p. Dissertação (Mestrado em Educação)- Universidade Católica de Brasília (UCB), Brasília, 2014.

WORLD BANK. Governance and development. Washington, D. C.: Oxford University Press, 1992.

WORLD ECONOMIC OUTLOOK DATABASE. International Monetary Fund. Abril de 2019. Disponível em: https://databank.worldbank.org/data/download/GDP.pdf. Acesso em: 3 jun. 2019.

\section{Sobre autores:}

Angela Mara Sugamosto Westphal: Doutoranda em Educação pela Pontifícia Universidade Católica do Paraná (PUC-PR). Mestre em Educação pela Universidade Católica de Brasília (UCB). Analista de Ciência e Tecnologia da CAPES. E-mail: angelasugamosto@gmail.com, Orcid: http://orcid.org/0000-0003-1990-1100

Maria Lourdes Gisi: Pós-doutora em Educação na Universidade de Genebra/Suíça. Doutora em Educação pela Universidade Estadual Paulista “Júlio de Mesquita Filho" (UNESP), Marília, SP. Professora Titular no Programa de Pós-Graduação em Educação da Pontifícia Universidade Católica do Paraná (PUC-PR). E-mail: gisi.marialourdes@gmail.com, Orcid: http://orcid.org/0000-0002-0474-474X 